\title{
Women's suggestions on how to improve the quality of maternal and newborn hospital care: a qualitative study in Italy using the WHO standards as framework for the analysis
}

\author{
Marzia Lazzerini", Chiara Semenzato, Jaspreet Kaur, Benedetta Covi and Giorgia Argentini
}

\begin{abstract}
Background: A recent systematic review identified very few studies on women's views on how to improve the quality of maternal and newborn care (QMNC). This study aimed at exploring the suggestions provided by women, after hospital delivery in Italy, on how to improve the QMNC.

Methods: A questionnaire, containing open questions to capture suggestions on how to improve QMNC, was used to collect suggestions of mothers who gave birth a tertiary care referral hospital in Northeast Italy, between December 2016 and September 2018. Two authors independently used thematic analysis to analyse women's comments, using the WHO Standards for improving the QMNC as framework for the analysis.

Results: Overall 392 mothers provided a total of 966 comments on how to improve the QMNC. Overall 45 (11.5\%) women made suggestions pertinent to "provision of care", 222 (56.6\%) to the "experience of care", 217 (55.4\%) to "physical or to human resources". The top five suggestions were: 1) increase presence of a companion during the whole hospitalization (28.3\% of women); 2 ) improve bathrooms and showers (18.4\%); 3) improve effective communication from staff (14.0\%); 4) improve staff professionalism, empathy, and kindness (13.5\%); 5) increase support and information on how to provide care to the newborn (11.2\%). Overall, 158 (16.4\%) suggestions could not be classified in any WHO Standards, and among these most (72.1\%) were related to physical structures, such as: decrease the number of patients per room; create areas for visitors; avoid case mixing in the same room; reduce rooming-in/ better support the mother. Overall 62 (15.8\%) women expressed appreciations.

Conclusions: Collecting the women's views on how to improve the QMNC after hospital delivery highlighted critical inputs on aspects of care that should be improved in the opinion of service-users. More investments should be made for establishing routine systems for monitoring patients experience of care. Data collected should be used to improve QMNC. WHO Standards may be further optimized by adding items emerging as relevant for women in high-income countries.
\end{abstract}

Keywords: Women, Newborn, Service users, Quality of care, Standards, WHO, Hospital, Qualitative study

\footnotetext{
* Correspondence: marzia.lazzerini@burlo.trieste.it

WHO Collaborating Centre for Maternal and Child Health, Institute for Maternal and Child Health IRCCS Burlo Garofolo, Via dell'Istria 65/1, 34137 Trieste, Italy
}

C C The Author(s). 2020 Open Access This article is licensed under a Creative Commons Attribution 4.0 International License, which permits use, sharing, adaptation, distribution and reproduction in any medium or format, as long as you give appropriate credit to the original author(s) and the source, provide a link to the Creative Commons licence, and indicate if changes were made. The images or other third party material in this article are included in the article's Creative Commons licence, unless indicated otherwise in a credit line to the material. If material is not included in the article's Creative Commons licence and your intended use is not permitted by statutory regulation or exceeds the permitted use, you will need to obtain permission directly from the copyright holder. To view a copy of this licence, visit http://creativecommons.org/licenses/by/4.0/ The Creative Commons Public Domain Dedication waiver (http://creativecommons.org/publicdomain/zero/1.0/) applies to the data made available in this article, unless otherwise stated in a credit line to the data. 


\section{Background}

Health 2020, the World Health Organisation (WHO) policy framework and strategy for the European Region [1], identifies quality of maternal and newborn care (QMNC) as a key determinant of maternal and newborn health outcomes, of health services expenditures, and as a crucial aspect of human rights. The importance of QMNC - which includes the dimension of patient-centred care - is also recognised by many other policy documents, including the WHO Global Strategy for women and children, the agenda for Sustainable Development Goals (SDGs), and it is in general is widely accepted by many other groups and organizations [2-5]. In the recent years there has been an increasing recognition on the fact that cross the world many women experience low quality care, and often disrespectful, abusive, or neglectful treatment during childbirth in facilities [6-10]. The importance on providing a good "experience of care" during childbirth is now emphasized in many recent documents, such as the "WHO Guidelines of Intrapartum Care for a Positive Childbirth Experience" [11].

Despite high-income countries in the European Region, including Italy [6], are characterized by low maternal and newborn mortality when compared to resources settings, yet several challenges in the QMNC persist. Current evidence suggests that in many high-income countries within the European Region the implementation of good practices based on evidence is still unsatisfactory [12-17], with a diffuse tendency to overmedicalisation [12, 15-17], and, frequently, a culture of "paternalism", with low participation of women in decision making [17]. In general, even in high-income countries, such as Italy mothers' qualitative perception of the experience of care is very not included in the routine assessment of the QMNC, and not considered for health services planning purposes [6].

Among the many initiatives aiming at improving the QMNC, in 2015 the WHO developed a framework which defines clearly key components of quality services for the mother and the newborn [18]. The WHO framework identifies the following three key dimensions of the QMNC: 1) "provision of care", including evidence-based practices, efficient information and referral systems; 2) "experience of care" including effective communication, respect, dignity and emotional support; 3) the availability of resources, including "competent, motivated human resources" and "appropriate physical resources" [18]. Based on these eight key dimensions of the framework [18], WHO developed eight Standards for improving the QMNC in health facilities", further declined into 31 quality statements, and over 300 quality measures, in an attempt of defining what health care planners, managers and care providers should ensure to guarantee high-quality care around the time of birth [19]. The WHO Standards were developed based on the existing literature and through a large consultation with experts and represent a very comprehensive set of measures related to the QMNC [19]. However, as documented in a recent systematic review [20], what matters to women during childbirth is still relatively poorly documented. Specifically, among 35 studies identified by the systematic review [20], all had a very small sample (ie, maximum 35 women), with the only exception being a study in Sweden (908 women), one in Australia (202 women), and one in India (85 women) [21-23]. Additionally, these studies did not documented suggestions of women, collected after delivery, on how to improve QMNC, but rather expectations before delivery $[21,22]$ or changes in cultural belief through generations [23]. None study from Italy has ever reported women's suggestions on how to improve the QMNC [20]. This qualitative study aimed at exploring the suggestions provided by women, after hospital delivery in Italy, on how to improve the QMNC.

\section{Methods \\ Study design}

This was a qualitative study, and in reporting it, we used the Standards for Reporting Qualitative Research [24]. (Supplementary Table 1).

\section{Setting}

The study was conducted between December 2016 and September 2018 in a large public tertiary level university referral hospital in Northeast Italy, the Institute of Research for Maternal and Child Health Burlo Garofolo, Trieste. Every year about 1700-1800 mothers give birth in the hospital.

\section{Data collection}

Mothers who gave birth in the hospital from December 2016 to September 2018 were invited to participate. Exclusion criteria were: maternal death, perinatal death (including stillbirth), refuse to participate, psychiatric or psychosocial problems with inability to fill in the questionnaire (as assessed by a psychiatrist or by a social assistant), age under 18 years old, and language barriers.

Data were collected using a field-tested, anonymous, selfadministrated, questionnaire in the local language (Italian). The questionnaire and the procedure for its validation, together with preliminary results of a survey conducted have been reported in a previous publication [25]. Briefly, the questionnaire was developed after a large review and thematic analysis of other existing tools and reference standards [25]. The questionnaire was tested in a sample of voluntary mothers, with different characteristics (age, education, parity, etc) who reviewed the questionnaire individually and provided a written feedback [25]. The draft version of the questionnaire was also submitted to a panel of experts with experience on research in QMNC issues (obstetricians, neonatologists, midwives, epidemiologists), 
for content validity and construct coherence [25]. Experts reviewed the questionnaire independently in a firth phase and in an extensive group discussion meeting, in a second phase [25]. The questionnaire was optimized according to the feedback received, and the final version was re-tested in a second group of voluntary mothers [25]. The questionnaire included open questions to collect any type of suggestion, comment or request from women on how to improve the QMNC. Mothers could decide on a voluntary basis whether to fill these open questions. The questionnaire also collected socio-demographic information of women, and a question on women satisfaction with the care received, scored on a Likert scale from 1 (minimal) to 10 (maximal) satisfaction [25]..

The questionnaire and the overall objectives of the study were presented to the mothers in the post-delivery period, during their stay the post-delivery ward (usually less than 3 days after delivery), by a trained research midwife, not involved in case management. Mothers were enrolled from Monday to Saturday, and they could return the filled questionnaires directly to the operator, or in a dedicated box available in the ward 24/24 $\mathrm{h}$ and $7 / 7$ days.

\section{Data analysis}

Two authors independently created an Excel spreadsheet of all women's comments, and used thematic analysis methods to conduct initial open coding on each relevant text unit [26]. The women's comments were classified according to the WHO framework and Standards $[18,19]$. The WHO framework and Standards $[18,19]$ include three main domains ("experience of care", "provision of care" and "resources"), eight Standards and 31 Quality Statements. The eight WHO Standards were used as major themes, and the 31 Quality Statements were used as second level themes. Each theme was then further expanded, based on the themes emerging from women's comments, to develop the final axial coding scheme. Axial coding is widely accepted in qualitative literature as a sufficient method to disaggregate core themes during qualitative analysis [26-28]. Two researchers applied independently the axial codes systematically to the data by hand-sorting the text units into themes and sub-themes. Any theme emerging from women's comment and not included in the WHO standard was added as additional theme. We calculated the total number of comments and the frequency of comments in each theme, using two distinct denominators: number of women $(N=392)$; total comments $(N=966)$. If a comment pertained to more than one theme (eg, both to experience and provision of care), we opted for inputting it in both themes, in order to capture all relevant themes. If the content of one comment was unclear to both researchers, it was labelled as "unclear". Comments without any specific suggestion were classified as follows: appreciations, negative comments, unclear. Any disagreements on thematic analysis was solved by discussion between the two authors and consensus sough through two senior authors. Results are reported in tables and text.

\section{Results}

\section{Women's characteristics}

Overall 392 mothers provided 966 comments related on how to improve the QMNC. Characteristics of mothers are reported in Table 1 . The median age was 33.5 years (range $=18-46)$ and $91.6 \%$ had an Italian nationality. More than half of mothers $(56.5 \%)$ were primiparous, and nearly all $(98.7 \%)$ had a single pregnancy. Over half (58.2\%) were highly educated (Bachelor's degree or specialist degree). In terms of key outcomes, overall 74 (18.9\%) had an elective caesarean section, while 116 (29.6\%) had an emergency caesarean section, while 43 (11.0\%) had their baby in the intensive care unit. Most of mothers $(68.1 \%)$ were highly satisfied with the care received, while only $40(10.2 \%)$ were not satisfied. There were not significant differences between mothers who provided suggestion and those who did not, except for slightly more mother in the first group having a post-

Table 1 Characteristics of mothers

\begin{tabular}{ll}
\hline & $N(\%)$ \\
& $(\boldsymbol{N}=392)$ \\
\hline Age, median (range) & $33.5(18-46)$ \\
Italian nationality & $360(91.6)$ \\
Primiparous & $222(56.5)$ \\
Multiple pregnancy & $5(1.3)$ \\
Education & \\
No formal education & $0(0)$ \\
Primary school & $1(0.3)$ \\
Lower secondary education & $23(5.9)$ \\
Upper secondary education & $138(35.1)$ \\
Degree & $153(38.9)$ \\
Post-graduate studies & $76(19.3)$ \\
Caesarian section & \\
Elective cesarean section & $40(10.2)$ \\
Emergency cesarean section & $55(14.0)$ \\
Baby in intensive care unit & $43(11.0)$ \\
Maternal satisfaction with the care received ${ }^{a}$ & \\
Not satisfied & $40(10.2)$ \\
Fairly Satisfied & $83(21.2)$ \\
Highly satisfied & $267(68.1)$ \\
Missing & $2(0.5)$ \\
\hline
\end{tabular}

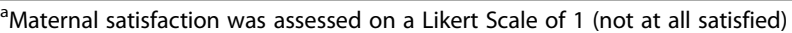
to 10 (maximum satisfaction). Women with a score 1 to 5 were considered "Not satisfied". Women with a score of 6-7 were considered "Fairly satisfied". Women with a score equal or above 8 were considered "Highly satisfied" 
graduate education $(19.3 \%$ vs $13.3 \%, p=0.02$ see Supplementary Table 2).

\section{Women's suggestions on how to improve QMNC}

Most women made more than one suggestion, with a mean rate of 2.5 suggestions per women (median 2.0, range 1 to 10) (Table 2). Overall 45 (11.5\%) women made suggestions pertinent to provision of care, $222(56.6 \%)$ to the experience of care, 217 (55.4\%) to human and physical resources.

Overall, 158 (16.4\%) suggestions could not be classified in any WHO Standards. In addition, 89 (9.2\%) comments did not include any practical suggestion.

The top five women's suggestions were: 1 ) increase presence of a companion during the whole hospitalization (28.3\% of women); 2) improve bathrooms and showers $(18.4 \%)$; 3) improve effective communication from staff $(14.0 \%)$; 4) improve staff professionalism, empathy, and kindness (13.5\%); 5) increase support and information on how to provide care to the newborn (11.2\%). Detailed results are reported in the following paragraphs.

\section{Provision of care}

Among these 48 suggestions, half [24] were requests of improving counselling and support on breastfeeding, while about one third [17] were related to options of pain relief during labour and childbirth (Table 3). For example, a mother wrote "There is need for more anaesthetists $24 / 24 \mathrm{~h}$ for performing epidural: I had terrible pain and I felt that because of this my labour was not progressing".

There was a low number of suggestions related to the other WHO Quality measures of WHO Standard 1 ("Every woman and newborn receives routine, evidencebased care and management of complications during labour, childbirth, post-partum, according with WHO Guidelines"), and zero comments related to the WHO Standard 2 ("The health information system enables use of data to ensure early, appropriate action to improve the care of every women and newborn") and the WHO Standard 3 ("Every woman and newborn with condition that cannot be dealt with effectively with the available resources is appropriately referred").
Overall 10 women made suggestions that could not be classified in any WHO Standards, with the most frequent being improving access to labour/birth in water (1.8\% of total women).

\section{Experience of care}

The domain of experience of care accounted for 316 (32.7\%) of total comments, with over half of women (56.6\%) providing suggestions (Table 2). Additionally, the top one most frequent women's request among total comments pertained to this domain, namely: increase presence of a companion during the whole period of hospitalization (28.3\% of women) (Table 4). For example, one mother wrote: "father should not be treated as the other visitors; they should be allowed to live with us this experience, they should stay with us all the time they want and can", while one added "more support from fathers, with more flexible access to the ward could help us to rest; we need it so much, and it is in the interest of the baby".

Overall, about one out of six (14.0\%) of mothers highlighted the need for improving communication. For example, one mother wrote: "more information is needed for the mother", while another added: "we need to be listening to, we need doctors to be able to listen more to what are our needs".

Other frequent women's requests were: strengthened coordinated care and improved communication among hospital staff (7.7\%). For example, a mother wrote "every staff says a different thing, and this is confusing, communication among staff should be improved", while another added: "communication to patients need to be respectful, sometimes I felt treated as I was not able to understand nor to do nor to decide anything".

Overall 34 women's requests in this area were not related to any WHO Standard, with the most frequent being the need of better regulating visiting times for relatives (6.4\% of women).

\section{Human and physical resources}

The domain of human and physical resources accounted for 355 (36.7\%) of total comments, with over half of women $(55.4 \%)$ providing suggestions in this area (Table 2).

Table 2 Number of women's suggestions by domain of quality of care

\begin{tabular}{lll}
\hline Domain of quality of care & $\begin{array}{l}\text { On total women } \\
(\boldsymbol{N}=392)^{a}\end{array}$ & $\begin{array}{l}\text { On total comments } \\
(\boldsymbol{N}=966)\end{array}$ \\
\hline Provision & $45(11.5)$ & $48(5.0 \%)$ \\
Experience & $222(56.6)$ & $316(32.7 \%)$ \\
Human and physical resource & $217(55.4)$ & $355(36.7 \%)$ \\
Not included in the WHO Standards & $136(34.7)$ & $158(16.4 \%)$ \\
Not including a suggestion & $89(9.2 \%)$ & $89(9.2 \%)$ \\
\hline
\end{tabular}

\footnotetext{
${ }^{a}$ Most women made more than one comment, therefore the total exceeds $100 \%$
} 


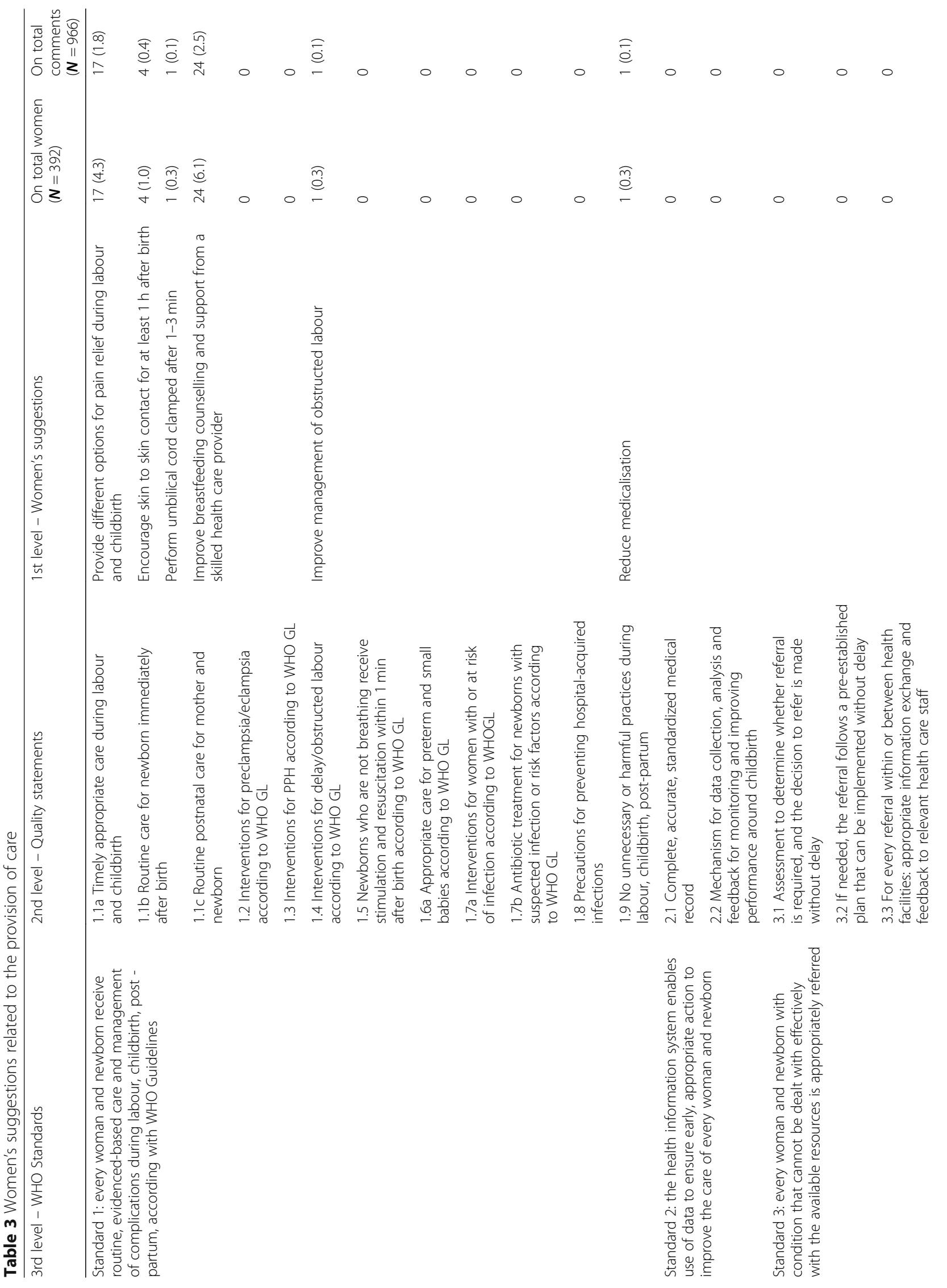




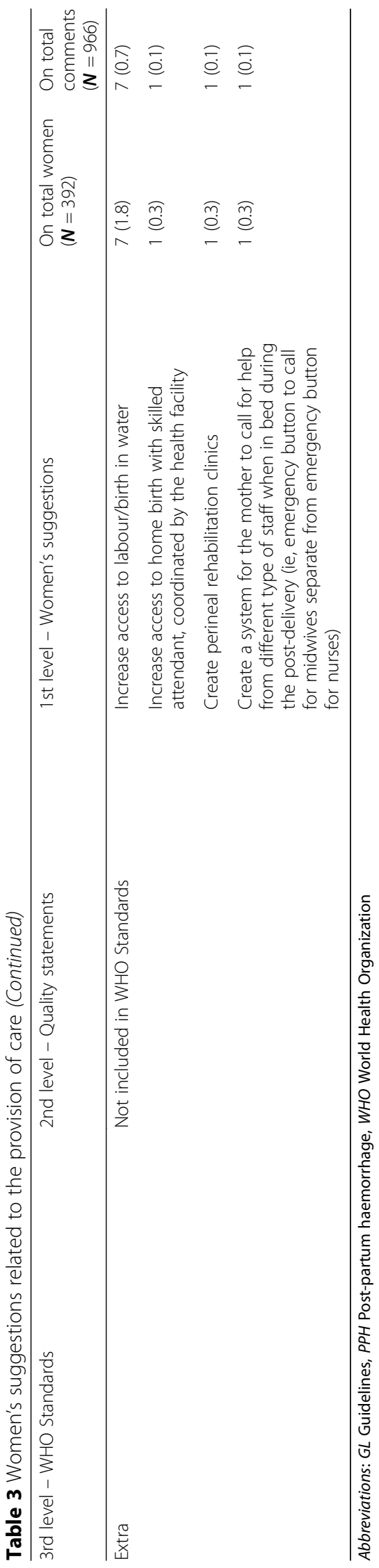




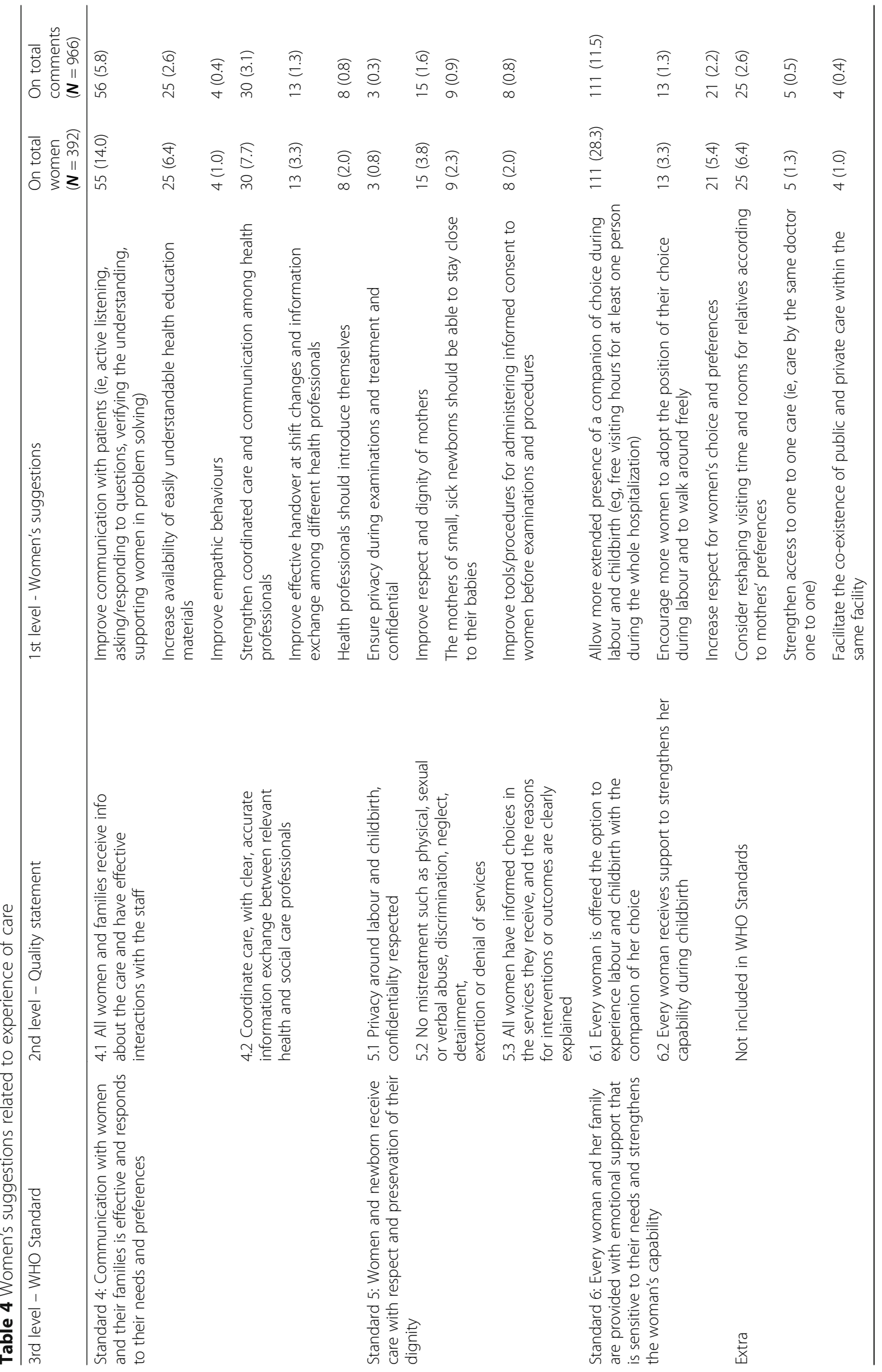


Additionally, three of the top five most frequent women's requests among total comments pertained to this area (Table 5): improve bathrooms and showers (18.4\% of total women); improve staff professionalism, empathy, and kindness (13.5\%); increase support and information on how to provide care to the newborn (11.2\%). For example, one mother reported "I had very different experience with two different midwives, while all staff should all be able to provide equally good care". Another added: "nurses should understand that most of mothers are at the first breastfeeding experience; they should be more patient and collaborative, and less judgmental; also, they should give more consistent advices".

Other frequent women's requests were improving rooms equipment $(8.9 \%)$ and increasing availability of hospital staff at any time when needed (8.2\%).

Overall 114 women's requests in this area were not related to any WHO standard, with the most frequent being: decreasing the number of patients per room $(7.4 \%$ of women); creating separated areas for visitors (5.9\%); improving quality of meals (4.8\%); avoid case mixing in the same room, such as separating women with involuntary termination of pregnancy from those in labour (3.6\%), and reducing strict rooming-in $24 / 24 \mathrm{~h}$ to allow the mother to rest or to shower (3.3\%).

\section{Comments without specific suggestions}

Among the 89 comments without any specific or practical suggestion, 62 (15.8\% of total women) were of appreciation, $18(4.5 \%)$ were negative complaints, and 9 (2.2\%) were unclear.

Among the comments of appreciation, about half (46.2\%) were general appreciations to the whole service, one third (28.3\%) were praising staff professionality, and the remaining were divided in equal parts among positive remarks related to the kindness of staff, and the structure of the ward. For example, one mother wrote: "I met competent and very sensitive staff in both delivery and post-partum departments". Another made this comment: "I felt really understood by all the staff and would recommend the structure to friends". While a third added "I always felt respected in my dignity and even during the visits I was respected".

\section{Discussion}

This study showed that collecting women's suggestions on how to improve QMNC at hospital level in Italy was feasible and extremely relevant, highlighting critical inputs on aspects of care that should be improved in the opinion of service-users. Most of mothers provided more than one inputs and requests for improving the QMNC. This is the first study in Italy documenting views of women, after giving birth in a hospital, on how to improve the QMNC: we were able to identify three previous research reporting on the women's experience of care during childbirth in Italy, but these did not include practical suggestions, as expressed by women, on how to improve it [25, 29, 30]. Additionally, this is the first study utilising the WHO Standards [19] as framework for the thematic analysis on women's suggestions on how to improve the QMNC, and may serve as model for future research. Strengths of the study include that had a relatively large sample size, when compared overall to existing literature [20,21].

Findings of this study are in line with existing evidences on women's requests on QMNC, as reported by other investigations. The most frequent women's request emerged in this study, ie, increase presence of a companion (made by about one third of women in our study) has been largely documented, together with the fear of being alone, in previous systematic reviews [20,31]. Key aspects of "experience of care", such as a request for privacy and confidentiality, effective communication and information, respect, empathy and continuity of care have been also widely documented $[20,31]$. Other themes relevant to the "resources" domain, such as the need for a safe and supportive environment, and the expectation for health professionals to be skilled, competent, sensitive and kind, in the delicate moment of childbirth, have emerged as key themes in studies conducted both in low-income and high-income countries [20,31]. Taken together this literature calls for more investments in establishing routine systems for collecting patients' suggestions on how to improve QMNC, as already recommended by WHO and others [19, 32]. Data collected should be used in practice for planning intervention to improve QMNC (19.32). This pilot study may be used as a model for future projects, aiming at improving women participation into health care planning.

Interestingly, in this study only a minority of mothers (11.5\%) made suggestions related to the domain of "provision of care", which includes all technical aspects of evidence-based care (such as mode of delivery, type of practices experienced). Exiting similar studies conducted in high-income countries $[19,22]$ seem to confirm that women tend to make few suggestions related to medical practices. For example, in an Australian study [22], women reported as unique expectation related to "provision of care" the desire of a vaginal birth (when compared to operative delivery or caesarean section), and other important aspects (eg, induction of labour, episiotomy etc) were not mentioned at all. The observation that in our study as well as in others [16] few mothers made suggestions related to the "provision of care" may have multiple explanations, including: lack of knowledge among mothers on "technical aspects" of care; cultural factors including different types of stereotypes (eg, tendency to low autonomy in these domains); low importance attributed by mothers to these aspects when compared to others (eg, newborn well-being); overall good practices with low need for improving the 


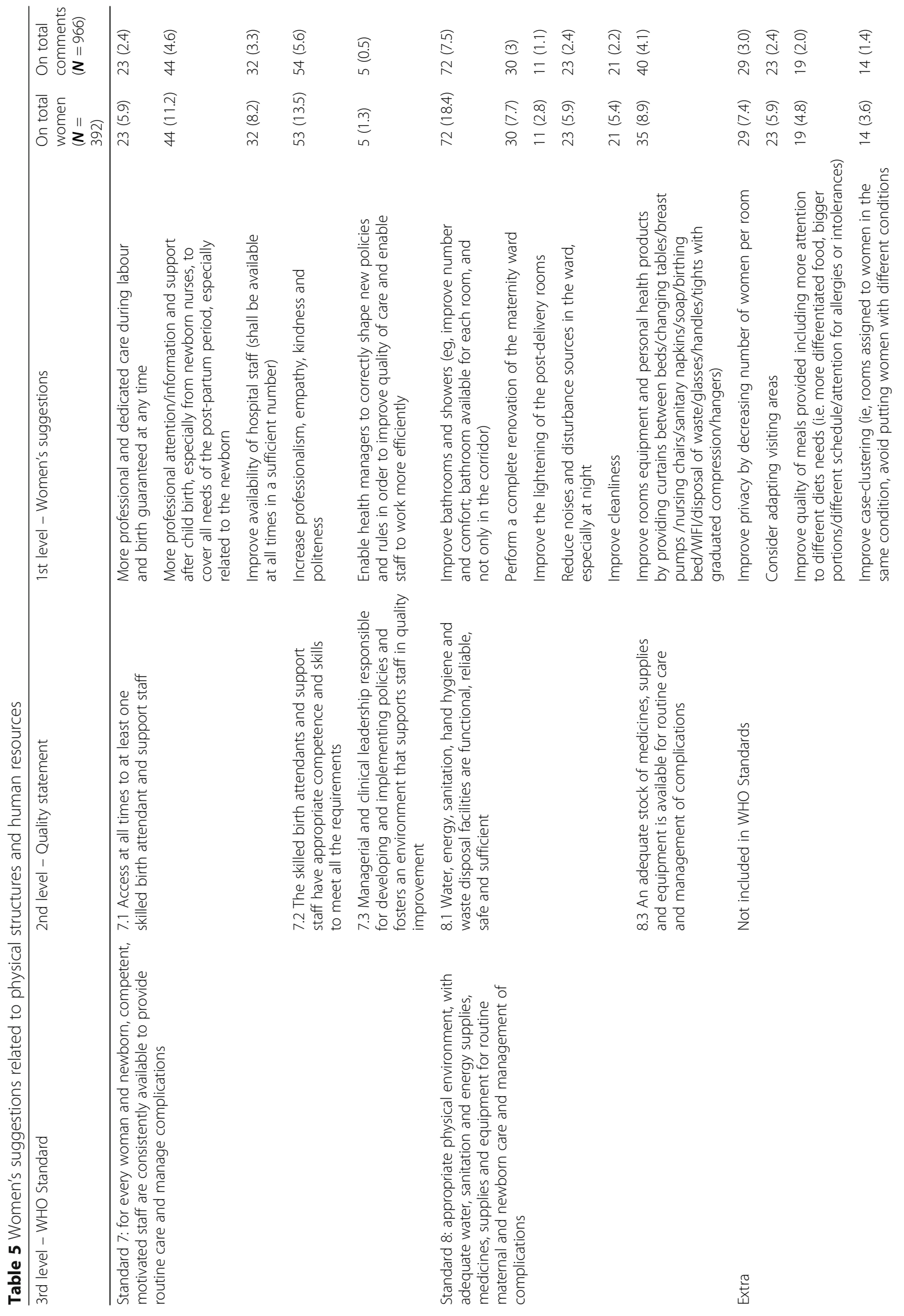




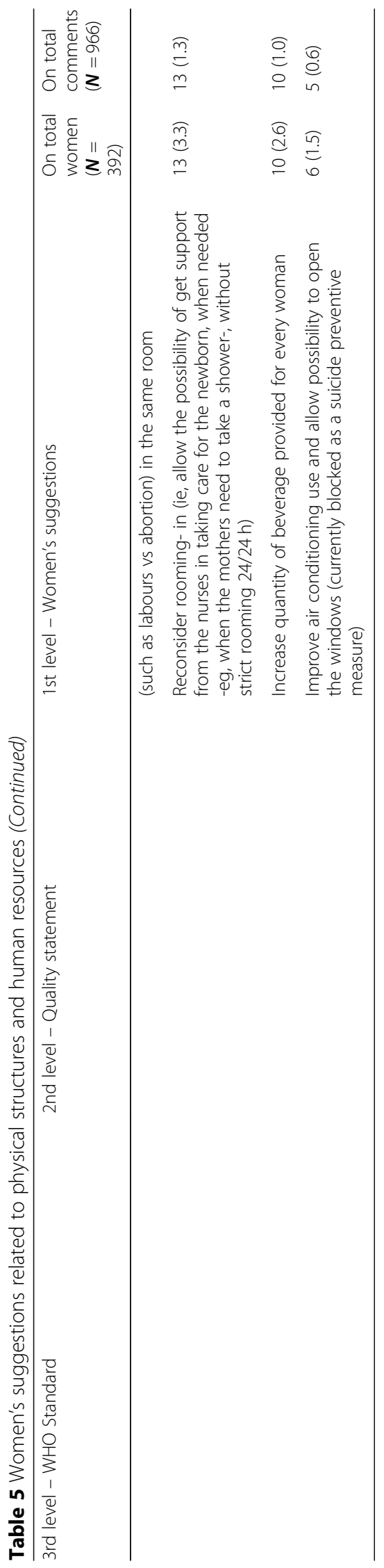


QMNC. Each of these factors may play a different role in a different contest. More studies should document factors affection women's opinion on "provision of care" in different settings.

This study identified, among overall women's requests, $16.4 \%$ themes currently not included in the WHO Standards, such as a request for more privacy, and for more flexible rooming in (ie, not strictly $24 / 24 \mathrm{~h}$ ) to allow the mother to rest or shower. These findings should be interpreted based on the characteristics of the setting and in the light of other women's suggestions - such as the request for higher presence of a companion, and better comfort in the rooms, suggesting that the problem is not rooming-in per se, but rather the lack of other adequate support systems for the mother in the immediate postdelivery-. Currently, there is little experience on the use of the WHO Standards [19], no standardized data collection tool for high-income countries, nor pre-defined data sources. Our results, in line with existing literature [11, 32] call for further research in this area. If confirmed by other studies, consideration should be given on whether to include the additional themes emerged in this study as important for women, among the WHO Standards.

We acknowledge that this study was conducted in one single facility in Italy, and as such findings are not generalizable to other Italian hospitals. Previous studies reported clear differences in practices (such as caesarean section rate) as well as in the experience of care among different geographical regions in Italy, and even among nearby facilities in the same region [6, 29]. For example, it is possible that the maternal and newborn outcomes influenced indirectly the perception of the QMNC with Halo effect, ie, the behavior, usually unconscious, of using evaluations based on things unrelated, to make judgments about something or someone [33, 34].

Additionally, we acknowledge that this study, due to lack on interpreter, did not to capture views of migrant women unable of talking the local language (Italian). Recent studies pointed out how the need of migrant women may focus on specific topics, such as: the need for information on how to access health services, the availability of trained interpreters, and developing capacities health care providers on how to respond to the health needs of women with different backgrounds, in a culturally appropriate way $[35,36]$. Similarly, women younger than 18 years were not included in the study, which therefore does not represent the views of adolescent mothers.

Finally, we acknowledge that the data collection tool (open questions to be filled on a voluntary basis) and the timing of administration (immediate post-partum) may have affected results. For example, some answers suggested that mothers may have much more to say, and this would deserve different data collection methods (eg. focus group). Additionally, soon after childbirth mothers may be more concentrated on the joy of having a baby than on the quality of care received. A Halo effect, with negative experiences being temporarily overshadowed in the immediate post-delivery by the excitement and joy of the moment, and later looming as time goes and memories become more realistic, has been previously described among women after delivery [33]. Additionally, although there were no major differences between mothers who provided their views and those who did not (Supplementary Table 2), we cannot exclude a selection bias. For example, it is possible that mothers who provided their views were those with more to say. However, it is also possible that women's' response rate was affected by other factors, such as individual psychological traits (eg, willingness to contribute, trust in the institution); contingency (eg, availability of time) or other factors. The ideal timing, tools and data collection methods for these types of studies have not been establish yet. Further research is needed to explore how mothers' views may vary over time, depending on the timing and types of questions asked, and maternal and newborn health outcomes. In general, more studies should be conducted to further explore mothers' suggestions and requests on how to improve QMNC in different regions in Italy, as well as in other countries.

Most importantly, data emergency from this and from similar studies should be used to improve QMNC. Efforts should be made for establishing routine systems for monitoring patients experience of care, and for ensuring that data collected are used for improving the quality of health services, as recommended by WHO and others [19, 32]. Still there is little evidence exploring the drivers of poor experience if care and even fewer studies documenting interventions to prevent it. As highlighted also by others [32], although studies and measurement remain important, we need to move beyond collecting data, and drive efforts for increasing accountability and for tracking and achieving change.

\section{Conclusion}

Collecting the women's views on how to improve the QMNC after hospital delivery highlighted critical inputs on aspects of care that should be improved in the opinion of service-users. More investments should be made for establishing routine systems for monitoring patients experience of care. Data collected should be used un practice to improve health service quality. WHO Standards may be further optimized by adding items emerging as relevant for women in high-income countries.

\section{Supplementary information}

Supplementary information accompanies this paper at https://doi.org/10. 1186/s12884-020-02893-0.

Additional file 1 Table S1. Standards for Reporting Qualitative Research (SRQR) Checklist. Table S2. Comparison with missing cases. 


\section{Abbreviations}

QMNC: Quality of Maternal and Neonatal Care; SDG: Sustainable Development Goals; WHO: World Health Organization; PPH: Post-Partum Haemorrhage; GL: Guidelines

\section{Acknowledgments}

The authors are grateful to all women providing their suggestions on how to improve the quality of maternal and newborn care.

\section{Authors' contributions}

ML conceived the study. BC collected the data. CS, JK and GA analysed data. $M L$ drafted the manuscript with contributed from all authors, all authors reviewed the draft. The author(s) read and approved the final manuscript.

\section{Funding}

This study was funded by the Institute for Maternal and Child Health IRCCS Burlo Garofolo.

\section{Availability of data and materials}

The datasets used and/or analysed during the current study are available from the corresponding author on reasonable request.

\section{Ethics approval and consent to participate}

Ethical approval was obtained from the Independent Ethical Review Board of the IRCCS Burlo in March 2016 (number protocol number: 617/2016).

Participants to the survey were informed about the objectives and methods of the study, including their rights in declining participation, and signed an informed consent before responding the questionnaires. Anonymity in data collection was ensured by not collecting any information that could disclose participants' identity.

\section{Consent for publication}

Consent was obtained from participants who answered the questionnaire to report data, in aggregate form, in peer reviewed journals publications.

\section{Competing interests}

The authors declare that they have no competing interests.

Received: 29 November 2019 Accepted: 24 March 2020

\section{Published online: 06 April 2020}

\section{References}

1. Word Health Organization. Health 2020. A European policy framework and strategy for the 21st century. Copenhagen: Word Health Organization; 2013.

2. World Health Organization. Promoting health through the life-course. Global Strategy for Women's, Children's and Adolescent's Health 2016-2030. Geneva: Word Health Organization; 2015.

3. United Nation. Sustainable Development knowledge Platform. Transforming our World: The 2030 Agenda for sustainable development. New York: United Nations; 2015.

4. Spotlight on Sustainable Development (2016). Development Alternatives with Women for a New Era (DAWN). The "Health SDG": Some progress, but critical concerns remain. https://www.2030spotlight.org/en/book/605/ chapter/ii3-health-sdg-some-progress-critical-concerns-remain (accessed 15 Jun 2018).

5. White Ribbon Alliance (2018). https://www.whiteribbonalliance.org/vision/ ()

6. Evento nascita, il Rapporto CeDAP, 2015 Direzione Generale della Digitalizzazione, del Sistema Informativo Sanitario e della Statistica, Ufficio di statistica Rome, Italy, 2015. http://www.salute.gov.it/portale/news/p3_2_1_ 1_1.jsp?lingua=italiano\&menu=notizie\& $p=$ dalministero\&id=3446 (accessed 26 July 2019).

7. Freedman LP, Kruk ME. Disrespect and abuse of women in childbirth: challenging the global quality and accountability agendas. Lancet. 2014 384(9948): $42-4$

8. Bohren MA, Vogel JP, Hunter EC, Lutsiv O, Makh SK, Souza JP, Aquiar C, Saraiva Coneglian F, Diniz AL, Tunçalp Ö, Javadi D, Oladapo OT, Khosla R, Hindin MJ, Gülmezoglu AM. The Mistreatment of Women during Childbirth in Health Facilities Globally: A Mixed-Methods Systematic Review. PLoS Med. 2015;12(6):e1001847 discussion e1001847.

9. Bohren MA, Mehrtash H, Fawole B, Maung TM, Balde MD, Maya E, Thwin SS, Aderoba AK, Vogel JP, Irinyenikan TA, Adeyanju AO, Mon NO, Adu-Bonsaffoh
K, Landoulsi S, Guure C, Adanu R, Diallo BA, Gülmezoglu AM, Soumah AM, Sall AO, Tunçalp Ö. How.women are treated during facility-based childbirth in four countries: a cross-sectional study with labour observations and communitybased surveys. Lancet. 2019:394(10210):1750-63.

10. Miller S, Abalos E, Chamillard M, Ciapponi A, Colaci D, Comandé D, Diaz V, Geller S, Hanson C, Langer A, Manuelli V, Millar K, Morhason-Bello I, Castro CP, Pileggi VN, Robinson N, Skaer M, Souza JP, Vogel JP, Althabe F. Beyond too little, too late and too much, too soon: a pathway towards evidence-based, respectful maternity care worldwide. Lancet. 2016;388(10056):2176-92.

11. Brizuela V, Leslie HH, Sharma J, Langer A, Tunçalp Ö. Measuring quality of care for all women and newborns: how do we know if we are doing it right? A review of facility assessment tools. Lancet Glob Health. 2019;7(5):e624-32.

12. World Health Organisazation. WHO recommendations: intrapartum care for a positive childbirth experience. Geneva: World Health Organisazation; 2018.

13. Shaw D, Guise JM, Shah N, et al. Drivers of maternity care in high-income countries: can health systems support women-centred care? Lancet. 2016; 388:2282-95.

14. Flenady V, Wojcieszek AM, Middleton P, et al. Stillbirths: recall to action in high-income countries. Lancet. 2016;387:691-702. https://doi.org/10.1016/ S0140-6736(15)01020-X.

15. European Perinatal Health Reporth. Health and Care of Pregnant Women and Babies in Europe in 2010. https://www.europeristat.com/images/doc/ Peristat\%202013\%20V2.pdf (accessed 26 July 2019).

16. University of Oxford (2018). National Maternity Survey 2014. In: Redshaw M, Henderson J, editors. Safely delivered a national survey of women's experience of maternity care: The National Perinatal Epidemiology Unit; 2014. https://www.npeu.ox.ac.uk/maternity-surveys (accessed 08 Jun 2018).

17. Habiba M, Kaminski M, Da Frè M, Marsal K, Bleker O, Librero J, Grandjean H, Gratia P, Guaschino S, Heyl W, Taylor D, Cuttini M. Caesarean section on request: a comparison of obstetricians' attitudes in eight European countries. BJOG. 2006;113(6):647-56.

18. Tunçalp Ö, Were WM, MacLennan C, et al. Quality of care for pregnant women and newborns-the WHO vision. BJOG. 2015;122(8):1045-9. https:// doi.org/10.1111/1471-0528.13451.

19. World Health Organization. Sexual and reproductive health. Standards for improving quality of maternal and newborn care in health facilities. Geneva: Word Health Organization; 2016.

20. Downe S, Finlayson K, Oladapo OT, Bonet M, Gülmezoglu AM. What matters to women during childbirth: a systematic qualitative review. PLoS One. 2018;13(4):e0194906. https://doi.org/10.1371/journal.pone.0194906.

21. Rilby L, Jansson S, Lindblom B, Martensson LB. A qualitative study of women's feelings about future childbirth: Dread and delight. J Midwifery Womens Health. 2012;57:120-5. https://doi.org/10.1111/j. 1542-2011.2011.00113.

22. Fenwick J, Hauck Y, Downie J, Butt J. The childbirth expectations of a selfselected cohort of Western Australian women. Midwifery. 2005;21(1):23-35. https://doi.org/10.1016/.j.midw.2004.07.001.

23. Sharma B, Giri G, Christensson K, Ramani KV, Johansson E. The transition of childbirth practices among tribal women in Gujarat, India: A grounded theory approach. BMC Int Health Hum Rights. 2013;13:41. [Accessed 19th February 2018]. https://doi.org/10.1186/1472-698X-13-41.

24. O'Brien BC, Harris IB, Beckman TJ, Reed DA, Cook DA. Standards for reporting qualitative research: a synthesis of recommendations. Acad Med. 2014;89:1245-51.

25. Lazzerini M, Valente EP, Covi B, Semenzato C, Ciuch M. Use of WHO standards to improve quality of maternal and newborn hospital care: a study collecting both mothers' and staff perspective in a tertiary care hospital in Italy. BMJ Open Qual. 2019;8(1):e000525. https://doi.org/10.1136/ bmjoq-2018-000525.

26. Charmaz K. Constructing grounded theory. London: SageGoogle Scholar; 2006.

27. Thomas J, Harden A. Methods for the thematic synthesis of qualitative research in systematic reviews. BMC Med Res Methodol. 2008;8:45.

28. Lazzerini M, Ciuch M, Rusconi S, Covi B. Facilitators and barriers to the effective implementation of the individual maternal near-miss case reviews in low/ middle-income countries: a systematic review of qualitative studies. BMJ Open. 2018;8(6):e021281. https://doi.org/10.1136/bmjopen-2017-021281.

29. Skoko E, Ravaldi C, Vannacci A, Nespoli A, Akooji N, Balaam MC, Battisti A, Cericco M, lannuzzi L, Morano S, Downe S. Findings from the Italian Babies Born Better Survey. Minerva Ginecol. 2018;70(6):663-75. https://doi.org/10. 23736/S0026-4784.18.04296-X.

30. Ravaldi C, Skoko E, Battisti A, Cericco M, Vannacci A. Abuse and disrespect in childbirth assistance in Italy: a community-based survey. Eur J Obstet 
Gynecol Reprod Biol. 2018;224:208-9. https://doi.org/10.1016/j.ejogrb.2018. 03.055 .

31. Shakibazadeh E, Namadian M, Bohren M, et al. Respectful care during childbirth in health facilities globally: a qualitative evidence synthesis. BJOG. 2017. https://doi.org/10.1111/1471-0528.15015 Published Online First: 8 November.

32. Afulani PA, Moyer CA. Accountability for respectful maternity care. Lancet. 2019;394(10210):1692-3.

33. Simkin P. Just another day in a woman's life? Part II: nature and consistency of women's long-term memories of their first birth experiences. Birth. 1992; 19(2):64-81.

34. Keller AC, Bergman MM, Heinzmann C, Todorov A, Weber H, Heberer M. The relationship between hospital patients' ratings of quality of care and communication. Int J Qual Health Care. 2014;26(1):26-33. https://doi.org/10. 1093/intahc/mzt083.

35. Sami J, Quack Lötscher KC, Eperon I, Gonik L, Martinez de Tejada B, Epiney M, Schmidt NC. Giving birth in Switzerland: a qualitative study exploring migrant women's experiences during pregnancy and childbirth in Geneva and Zurich using focus groups. Reprod Health. 2019;16(1):112. https://doi. org/10.1186/s12978-019-0771-0

36. Watson $\mathrm{HL}$, Downe S. Discrimination against childbearing Romani women in maternity care in Europe: a mixed-methods systematic review. Reprod Health. 2017;14(1):1. https://doi.org/10.1186/s12978-016-0263-4.

\section{Publisher's Note}

Springer Nature remains neutral with regard to jurisdictional claims in published maps and institutional affiliations.

Ready to submit your research? Choose BMC and benefit from:

- fast, convenient online submission

- thorough peer review by experienced researchers in your field

- rapid publication on acceptance

- support for research data, including large and complex data types

- gold Open Access which fosters wider collaboration and increased citations

- maximum visibility for your research: over $100 \mathrm{M}$ website views per year

At BMC, research is always in progress.

Learn more biomedcentral.com/submissions 